\title{
Mitral valve surgery: to repair or replace?
}

Heart valve prostheses remain imperfect substitutes for the native valve. There are problems of tissue failure in bioprostheses $^{12}$ and the drawbacks of long term anticoagulation, predominantly with mechanical prostheses. ${ }^{3}$ There is a growing awareness that the native mitral valve annulus and chordae tendineae are essential components of normal ventricular morphology and function, ${ }^{45}$ and improved understanding of the pathological anatomy of mitral valve disease has encouraged the development of operations designed to repair the valve's structural components, singly or in combination. ${ }^{6}$ Improvements in noninvasive echocardiography and Doppler ultrasound techniques allow more accurate preoperative assessment of diseased valves ${ }^{7}$ while refinements in techniques for myocardial preservation give more intraoperative time for precise evaluation and reconstruction. There is growing evidence that mitral valve repair improves short and long term survival and is associated with fewer thromboembolic complications than valve replacement. ${ }^{8-16}$

The simplest conservative procedure, closed mitral valvotomy, was reported in $1925^{17}$ and remains an important operation though it is not generally regarded as a "repair" procedure. The earliest reports of mitral valve repair procedures, suture annuloplasty under direct vision and on cardiopulmonary bypass, were in $1957 . .^{19}$ Initial enthusiasm for this procedure was dispelled, however, by reports of high operative mortality and loss of clinical improvement in up to $50 \%$ of patients within three years. $^{2021}$

Valve replacement because of its more predictable results became the recommended procedure for mitral insufficiency. ${ }^{22}$ In the early 1970 s several groups, most notably Carpentier and colleagues, reported that, compared with replacement, mitral valve repair improved survival and functional state and reduced thromboembolic complications. ${ }^{89}$ Recently, more support for repair 'rather than replacement has been generated by David and colleagues. ${ }^{2324}$ They reported a postoperative increase in left ventricular end diastolic pressures and decreased ejection fractions when the chordae were disrupted in patients undergoing valve replacement, compared with repair or replacement when these structures were preserved..$^{23}$ Others, however, dispute these findings. ${ }^{14}$

Mitral valve reconstruction ranges from at its simplest, commissurotomy, through annuloplasty, to complex repair procedures, in which the chordae tendineae are refashioned and transplanted. ${ }^{62526} \mathrm{With}$ surgical repair good results depend on the precise evaluation of the underlying morphology of the mitral valve-its leaflets, annulus, commissures, chordae tendineae, and papillary muscles. ${ }^{6}$ Carpentier et al produced a classification of leaflet abnormalities and emphasised the need to tailor the repair procedure to the exact pathological process; they attributed previous poor repair results to a failure to do this. ${ }^{8} \mathrm{Complex}$ repair procedures have not been widely applied because they may be technically more difficult, demand greater subjective assessment, require increased intraoperative time, and have a longer learning curve and less predictable results than replacement (at least in the learning period). ${ }^{27}$ Intraoperative assessment of the efficacy of repair procedures is difficult and not entirely satisfactory. It has, until recently, relied on methods such as visual inspection for leakage after filling the ventricle, either during ventricular arrest or with an active beating heart. The increasing availability of transoesophageal or surface echocardiography at the time of surgery should, however, allow improved intraoperative assessment of the repair procedure and should reduce the likelihood of an unsatisfactory result. ${ }^{28}$

Which valves are suitable for reconstruction? There are no absolute rules but, generally, regurgitant valves are more suitable than stenotic valves for reconstructive procedures. One exception is the purely stenotic valve with non-calcified and pliable leaflets, predominantly seen in younger patients in developing countries. In such countries closed valvotomy is the usual treatment because cost precludes open valvotomies, which require extracorporeal circulation. The cost of radiographic facilities and catheters also controls the use of percutaneous balloon dilatation of such valves in developing countries.

Few surgeons would disagree that the end stage rheumatic mitral valve (typified by retracted, fibrotic and/ or calcified leaflets, and a fused subvalvar apparatus) requires replacement. In contrast, regurgitant mitral valves characterised by non-calcified floppy leaflets, annular dilatation, and elongated chordae are more amenable to repair-as are those with chordal rupture, which is frequently associated with floppy valves but may be idiopathic. Demographic changes and the decline in the incidence of rheumatic heart disease have increased the numbers of patients with floppy mitral valves that may be suitable for repair procedures. Indeed, pure mitral valve incompetence is now most commonly due to the floppy mitral valve syndrome (mitral valve prolapse), but such incompetence can also be congenital, idiopathic, ischaemic, infective, or cardiomyopathic. ${ }^{29-31}$

Duran suggested that up to $40 \%$ of all mitral valves are suitable for reconstruction ${ }^{25}$ and Carpentier estimated that $5 \%$ of aortic valves, $50 \%$ of rheumatic mitral valves, and $90 \%$ of floppy mitral valves are suitable for repair. ${ }^{27}$ Floppy mitral valve disease was the reason for $40 \%$ of the mitral valve surgery performed in 1141 patients at the Cleveland Clinic between 1985 and 1988 and was usually suitable for operative correction. ${ }^{26}$ The procedures needed for surgical repair include ring annuloplasty, chordal shortening, resection and transposition of a normal leaflet to fill defects created by resection of flail leaflets, and occasionally transposition of the papillary muscle head. ${ }^{2526}$

Several groups reported better short and long term survival and functional state accompanied by a reduction in thromboembolic and anticoagulant-related complications, endocarditis, and the need for reoperation after mitral valve repair compared with replacement. ${ }^{8-16}$ Unfortunately, substantial differences in preoperative characteristics in the repair and replacement groups, which could themselves influence outcome, make it difficult to draw conclusions 
from these studies. ${ }^{8-16}$ The possibility that improved survival in patients undergoing repair procedures may simply reflect selection of a population with less advanced disease is supported in a recent paper by Galloway and colleagues. ${ }^{16}$ This group compared operative and late results in patients with porcine valve replacements (975), mechanical valve replacements (169), and Carpentier type mitral valve reconstructions (280). Although operative and five year mortality were reduced in the repair group, multivariate analysis showed this to be an effect of younger age and better preoperative myocardial function rather than type of operation.

In view of the patient numbers and the expense and length of follow up that would be required, comparison of mitral valve reconstruction and replacement in a prospective randomised trial is unlikely; indeed it is questionable whether such a trial would be ethical or practical. It is as inappropriate to attempt to repair an end stage, calcified, retracted mitral valve with a densely fused subvalvar apparatus as to replace a stenotic valve with fused, noncalcified, pliable leaflets with a prosthetic valve. The increasing prevalence of degenerative valve disease and growing dissatisfaction with currently available prostheses is likely to result in an increasing number of repair procedures despite their being more technically demanding and requiring greater experience. It is likely, but as yet unproven, that reconstructive surgery of the mitral valve in appropriately selected patients will give better long term results and fewer complications than prosthesis insertion.

Improvements in non-invasive preoperative assessment of diseased valves allow a high degree of accuracy in predicting those in whom reconstructive procedures are likely to be successful. For rheumatic mitral disease repair is virtually always feasible (and highly desirable) for pure stenosis without significant calcification; and may be achieved by closed valvotomy, particularly if sinus rhythm is still present. Where regurgitation is a consequence of annular dilatation or the floppy valve syndrome, repair is also likely to be successful (as it is in rheumatic regurgitation if seen at an early stage). In contrast, the thickened, retracted, immobile, and calcified leaflets commonly seen in end stage rheumatic mitral valve disease in most Western countries are rarely suitable for repair.

Heart Transplant Unit,

DAVID P TAGGART

The Freeman Hospital

Newcastle-upon-Tyne

NE7 7DN

Department of Cardiac Surgery,

DAVID J WHEATLEY

Royal Infirmary,

Glasgow G31 2ER

1 Starr A, Grunkemeier GL. The expected lifetime of porcine valves. Ann Thorac Surg 1989;48:317-8.

2 Teoh KH, Ivanov J, Weisel RD, Darcel IC, Rakowski H. Survival and bioprosthetic valve failure. Ten-year follow-up. Circulation 1989; 80(suppl 1):8-15.

3 Edmunds LH Jr. Thrombotic and bleeding complications of prosthetic heart valves. Ann Thorac Surg 1987;44:430-45.

4 Spence PA, Peniston CM, David TE. et al. Toward a better understanding of the etiology of left ventricular dysfunction after mitral valve replacement: an experimental study with possible clinical implications. Ann Thora Surg 1986;41:363-71.

5 Hansen DE, Cahill PD, DeCampli WM, et al. Valvular ventricular interaction: importance of the mitral apparatus in canine left ventricular systolic performance. Circulation 1986;73:1310-20.

6 Carpentier A. Mitral valve reconstructive surgery. In: Jamieson SW, Shumway E, eds. Rob and Smith's operative surgery. 4th ed. London: Butterworths, 1986:405-14.

7 Bloomfield P, O'Boyle JE, Parisi AF. Non-invasive investigations for the diagnosis of mitral valve disease. In: Ionescu MI, Cohn LH, eds. Mitral valve disease : diagnosis and treatment. London: Butterworths, 1985:53-86.

8 Carpentier A, Deloche A, Dauptain J, et al. A new reconstructive operation for correction of mitral and tricuspid insufficiency. $J$ Thorac Cardiovasc Surg 1971;61:1-13.

9 Kerth WJ, Sharma G, Hill JD, Gerbode F. A comparison of the late results of replacement and of reconstructive procedures for acquired mitral valve replacement and of reconstructive procedures for
disease. J Thorac Cardiovasc Surg 1971;61:14-22.

10 Carpentier A, Chauvaud S, Fabiani JN, et al. Reconstructive surgery of mitral valve incompetence: ten-year appraisal. J Thorac Cardiovasc Surg 1980;79:338-48.

11 Yacoub M, Halim M, Radley-Smith R, McKay R, Nijveld A, Towers M Surgical treatment of mitral regurgitation caused by floppy valves: repair versus replacement. Circulation 1981;64(suppl II):210-6.

12 Abedo OA, Ross JK. Surgical treatment of ruptured mitral valve chordae A comparison between valve replacement and valve repair. Thorac Cardiovasc Surg 1984;32:139-42.

13 Perier P, Deloche A, Chauvaud S, et al. Comparative evaluation of mitral valve repair and replacement with Starr, Bjork, and porcine valve prostheses. Circulation 1984:70(suppl 1):187-92.

14 Angell WW, Oury JH, Shah P. A comparison of replacement and reconstruction in patients with mitral regurgitation. J Thorac Cardiovasc Surg 1987;93:665-74.

15 Sand ME, Naftel DC, Blackstone EH, Kirklin JW, Karp RB. A comparison of repair and replacement for mitral valve incompetence. $J$ Thorac of repair and replacement for
Cardiovasc Surg 1987;94:208-19.

16 Galloway AC, Colvin SB, Baumann FG, et al. A comparison of mitral valve reconstruction with mitral valve replacement: intermediate-term results. reconstruction with mitral valve $r$

17 Souttar HS. The surgical treatment of mitral stenosis. Br Med J 1925;ii: 603-6.

18 Lillehei CW, Gott VL, DeWall RA, Varco RL. Surgical correction of pure mitral insufficiency by annuloplasty under direct vision. Journal-Lancet (Minneapolis) 1957;77:446-9.

19 Merendino KA, Bruce RA. One hundred and seventeen surgically treated cases of valvular rheumatic heart disease: with preliminary report of two cases of mitral regurgitation treated under direct vision with aid of a pump oxygenator. JAMA 1957;164:749-55.

20 Bigelow WG, Kuypers PJ, Heimbecker RO, Gunton RW. Clinical assessment of the efficiency and durability of direct vision annuloplasty. Ann Surg 1961;154:320-9.

21 Ellis FH Jr, Callahan JA, McGoon DC, Kirklin JW. Results of open operation for acquired mitral valve disease. $N$ Engl $J$ Med 1965;272: 869-74.

22 Effler DB, Favaloro R, Groves LK. Heart valve replacement. Ann Thorac Surg 1965;1:4-24.

23 David TE, Uden TE, Strauss HD. The importance of the mitral valve apparatus in left ventricular function after correction of mitral regurgitation. Circulation 1983;68(suppl 2):76-82.

24 David TE, Burns RJ, Bacchus CM, Druck MN. Mitral valve replacement for mitral regurgitation with and without preservation of chordae tendineae. $J$ Thorac Cardiovasc Surg 1984;88:718-25.

25 Duran CG. Conservative surgery of the mitral valve-ring annuloplasties. In: Ionescu MI, Cohn . LH, eds. Mitral valve disease. Diagnosis and treatment. London: Butterworths, 1985:179-90.

26 Cosgrove DM. Mitral valve repair in patients with elongated chordae tendineae. Journal of Cardiac Surgery 1989;3:247-52.

27 Carpentier A. Cardiac valve surgery: the "French correction". J Thorac Cardiovasc Surg 1983;86:323-37.

$28 \mathrm{KyoS}$, Takamoto S, Matsumura M, et al. Immediate and early postoperative evaluation of results of cardiac surgery by transeosophageal twodimensional Doppler echocardiography. Circulation 1987;76(suppl V): Vimensional

29 McKay R, Yacoub MH. Clinical and pathological findings in patients with "floppy" valves treated surgically. Circulation 1973;48(suppl III):63-73.

30 Hanson TP, Edwards BS, Edwards JE. Pathology of surgically excised mitral valves: one hundred consecutive cases. Arch Pathol Lab Med 1985;109:823-8.

31 Olson LJ, Subramanian R, Ackermann DM, Orszulak TA, Edwards WD. Surgical pathology of the mitral valve: a study of 712 cases spanning 21 years. Mayo Clin Proc 1987;62:22-34. 